\title{
MAPEAMENTO GEOTÉCNICO DA FORMAÇÃO ROSÁRIO DO SUL NA REGIÃO METROPOLITANA DE PORTO ALEGRE
}

\author{
Rinaldo José Barbosa PINHEIRO \\ Regina Davison DIAS
}

\begin{abstract}
RESUMO
O objetivo do mapeamento da Formação Rosário do Sul é caracterizar geotecnicamente os solos e rochas que compõem esta formação de origem sedimentar que ocorre na Grande Porto Alegre. Os estudos são referentes à litologia e sua distribuição na área, ocorrência de solos residuais e transportados, ensaios laboratoriais e seu comportamento frente a aplicações geotécnicas. Estas aplicações visam, principalmente, a fornecer subsídios geotécnicos para alcançar um planejamento adequado das zonas urbanas e das zonas de possível expansão das cidades, em vista de seu constante crescimento.
\end{abstract}

\section{ABSTRACT}

The objective of the mapping of Rosário do Sul Formation, typical of the Great Porto Alegre region, is to characterize geotechnically soils and rocks of these sedimentary beds.

This study refers to the lithology, spacial distribution, presence of residual soils, laboratory testing and behaviour relative to geotechnical applications. These latter consist of geotechnical information necessary to urban planning, particularly with regard to city expansion.

\section{INTRODUÇÃO}

A formação Rosário do Sul é de caráter regional, cobrindo uma área do Estado do Rio Grande do Sul, que se estende do município de Gravataí até o município de São Gabriel, ao longo da Depressão Periférica. A figura 1 apresenta a localização e distribuição dos sedimentos da Formação Rosário do Sul, bem como um mapa geológico. A área de estudo é caracterizada litologicamente pela presença de rochas sedimentares pertencentes à Bacia do Paraná, sendo esta uma extensa depressão deposicional situada na parte centro-leste do continente sulamericano. Na Região Metropolitana de Porto Alegre, as principais ocorrências mapeadas da Formação Rosário do Sul se localizam nos municípios de Canoas, Gravataí, Cachoeirinha, Sapucaia, São Leopoldo, Novo Hamburgo e Triunfo. Este trabalho se insere em um de âmbito maior que visa ao mapeamento geotécnico de toda a Região Metropolitana de Porto Alegre, desenvolvido pelo Curso de PósGraduação em Engenharia Civil da Universidade Federal do Rio Grande do Sul, denominado "SIGEO" - Sistema de Informações Geotécnicas.

\section{MATERIAL E MÉTODOS}

Esta formação é caracterizada por formas de relevo suave, ocasionalmente por formas abruptas. A Formação Rosário do Sul só se faz presente através da fácies fluvial, constituída por arenitos e siltitos, ocasionalmente argilitos. A fácies fluvial é caracterizada por arenitos finos a muito finos com estratificação planoparalela típica, condicionada pelo ambiente de deposição; e arenitos, siltitos e argilitos de planície de inundação. As rochas desta formação apresentam, predominantemente, uma coloração avermelhada com tons rosa, amarelo, roxo e cinza. Os arenitos, geralmente, apresentam-se quartzosos com proporções variadas de feldspatos e minerais pesados em menor teor. Pedologicamente, os solos de maior ocorrência na Depressão Periférica, ao norte de Porto Alegre, são os Podzólicos VermelhoAmarelados e os Podzólicos VermelhoEscuros.

O mapeamento geotécnico tem sido usado como uma ferramenta que ajuda a definir e a fiscalizar a ocupação territorial, estabelecendo unidades geotécnicas e estudando o comportamento dos perfis de solos (ZUQUETTE \& GANDOLFI, 1987). O método adotado teve 
início por um estudo de escritório, com posterior investigação de campo, retirada de amostras e realização de ensaios de laboratório, segundo a metodologia de DIAS (1989). O estudo preliminar de escritório foi baseado, principalmente, em mapas geológicos onde são indicados tipos de rocha que fazem parte do substrato, ou que podem ser encontrados na superfície através de afloramentos, ou ainda podem estar recobertos por espessas camadas de solos, sedimentos e outros materiais. Como os mapas geológicos não fornecem dados referentes aos solos superficiais, buscou-se usar levantamentos de solos e topográficos. Os mapas topográficos foram usados para determinar zonas de possível variação pedológica. Através das informações foi realizada uma estimativa dos locais de ocorrência da formação, com a localização de perfis típicos com o objetivo de serem estudados. Ao verificar-se a concordância das unidades de solos e rochas previstas nos estudos preliminares de escritório com as encontradas na investigação de campo, foram escolhidos os perfis que melhor descrevem as características morfológicas da formação. Foram feitas amostragens do horizonte B e dos horizontes C e R. Após escolhidos os pontos de amostragem nos perfis, foram retiradas amostras deformadas e indeformadas geralmente em escavações, obtendo-se dessa forma amostras de maiores profundidades em perfis representativos para a realização de ensaios geotécnicos. A simbologia usada para a denominação dos perfis considera a classificação pedológica para os horizontes superficiais e a geológica para indicar o substrato, segundo DIAS \& MILITITSKY (1990).

\section{RESULTADOS E DISCUSSÃO}

Foram escolhidos perfis representativos para a realização de ensaios geotécnicos, sendo estudados os seguintes perfis:

PVa - Podzólico Vermelho-Amarelado com substrato arenito.

PEag - Podzólico Vermelho-Escuro com substrato argilito.

Ra,s - Litólico com substrato arenito e siltito.

As figuras 2, 3 e 4 apresentam características destes perfis. Nestas figuras, no item (a) constam os esquemas dos perfis (disposição das camadas ao longo da profundidade), no item (b) está o gráfico de variação do limite de liquidez (WL), limite de plasticidade (WP), índice de plasticidade (IP), teor de umidade natural (w) e o grau de saturação (s) com a profundidade. Uma tabela contendo a granulometria é apresentada no item (c). Somente estão tabela- dos os valores de areia média e fina, silte e argila. Nenhum dos horizontes apresentou a fração pedregulho e areia grossa. A atividade coloidal (Ac), densidade real dos grãos (Gs) e os índices físicos (peso esp. natural e seco e índice de vazios) também estão descritos para os três perfis estudados na mesma figura. O trabalho completo, com a realização de vários ensaios de laboratório, é descrito por PINHEIRO (1991) na sua dissertação de mestrado. Os ensaios de laboratório foram ensaios de caracterização, compactação e difratogramétricos (raios-x). Os ensaios para determinadas propriedades geotécnicas foram os de permeabilidade, compressibilidade, colapsividade, expansão e de resistência (cisalhamento direto, triaxial e compressão simples).

Essas pesquisas, referentes às investigações de grandes áreas, contribuem para o conhecimento do meio físico, principalmente devido à definição de parâmetros geotécnicos que condicionam a execução das obras de engenharia. Alguns parâmetros, descritos abaixo, acompanham a carta geotécnica.

\subsection{Drenagem}

A região é caracterizada por uma drenagem dentrítica. Em geral não ocorrem ravinamentos profundos, exceto quando são removidos os horizontes superficiais, deixando o horizonte $\mathrm{C}$ de arenito exposto às intempéries. $\mathrm{O}$ horizonte B apresentou coeficiente de permeabilidade da ordem de $10^{-5} \mathrm{~cm} / \mathrm{seg}$. Os solos do horizonte $\mathrm{C}$ de arenitos e siltitos apresentaram coeficiente de permeabilidade entre $10^{-5}$ e $10^{-6}$ $\mathrm{cm} / \mathrm{seg}$. Já o arenito apresentou valores em torno de $10^{-6} \mathrm{~cm} / \mathrm{seg}$ e o siltito, valores de $10^{-7} \mathrm{~cm} / \mathrm{seg}$, ambos classificados como rochas sedimentares brandas.

\subsection{Expansão}

Os solos ensaiados na umidade natural não apresentaram valores de expansão significativos, devido ao elevado grau de saturação. Em ensaios realizados em amostras secas, após cinco dias, verificou-se que a pressão de expansão não foi significativa no horizonte $\mathrm{C}$ residual de arenito, com pressão de expansão de no máximo $12.5 \mathrm{kN} / \mathrm{m}^{2}$. O horizonte $\mathrm{C}$ de argilito resultou em valores de pressão da ordem de $200 \mathrm{kN} / \mathrm{m}^{2}$ e o horizonte R, de siltito de 100 $\mathrm{kN} / \mathrm{m}^{2}$. Os resultados dos ensaios difratogramétricos apresentaram como argilomineral predominante - nos horizontes de alteração de arenito, na rocha arenítica e siltítica - a caulinita, com traços de montmorilonita e mica nos horizontes siltosos. Já nos horizontes de alteração de argilito, o argilomineral predominante é a montmorilonita. 
Baseado nos Mapas do: DNPM(1989) RADAM BRASIL (1986) COULON (1973)

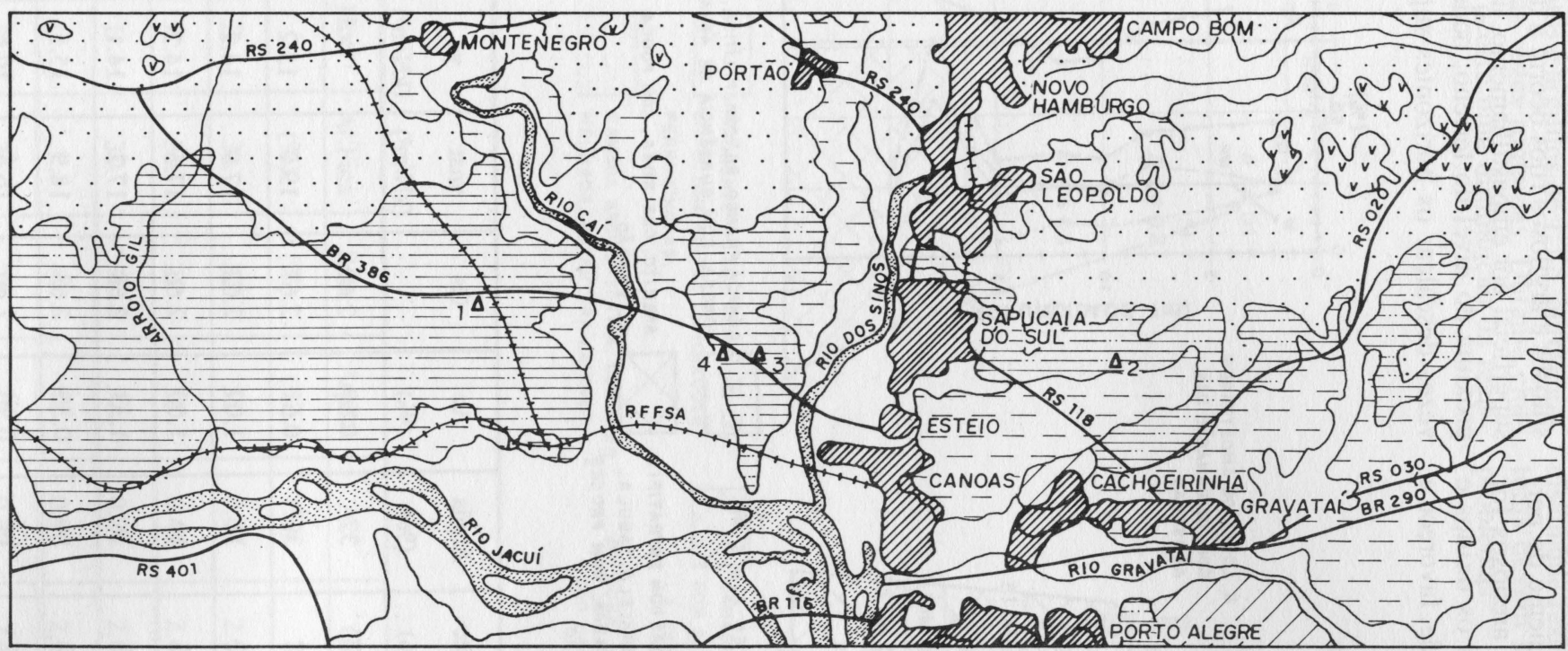

FIGURA 1.

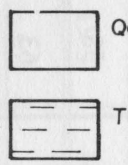
Odf/Qtf Depósitos fluviais e turfeiras.

Q Leques Aluviais - eluviōes e colu viōes (inclui depósitos das forrng çōes Gravataí, Serra de Tapes Graxaim.

\section{CONVENÇŌES} $\because \because$ TRJb Formaçāo Botucatu - arenitos

E...-. TRrs Formaçāo Rosário do Sul-arenitos intercalados $\mathrm{c} /$ siltitos de origem Rios fluvial e argilitos e siltitos da planicie de inundaçāo.

ESCALA O $25050075010001250 \mathrm{~km}$
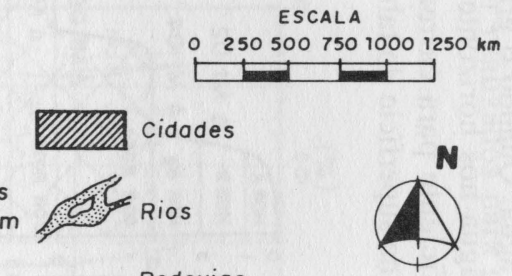

"v"v JKsg Formaçāo Serra Geral

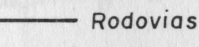

$\Delta$ Perfis investigados
Formação Rio Bonito - siltitos com carvão. 


\subsection{Estabilidade de cortes}

A estratificação plano-paralela nos arenitos, nesta região, favorece a estabilidade dos cortes. Principalmente, devido ao baixo ângulo de mergulho das camadas. Outro fator muito importante na estabilidade destes cortes é a presença de água. Quando o gradiente de percolação da água nos horizontes arenosos for somente suficiente para carrear os óxidos e depositá-los na superfície do talude, favorece a estabilidade, formando, portanto, uma película de 1 a $2 \mathrm{~mm}$ de espessura que protege da erosão superficial pela percolação da água. Quando o gradiente for elevado, começa a surgir a erosão subsuperficial, muitas vezes provocando a ruptura do talude. Nos horizontes siltosos e argilosos rijos ocorre a desagregação superficial por empastilhamento, na parte mais próxima do nível do terreno, podendo muitas vezes descalçar os horizontes superiores dos
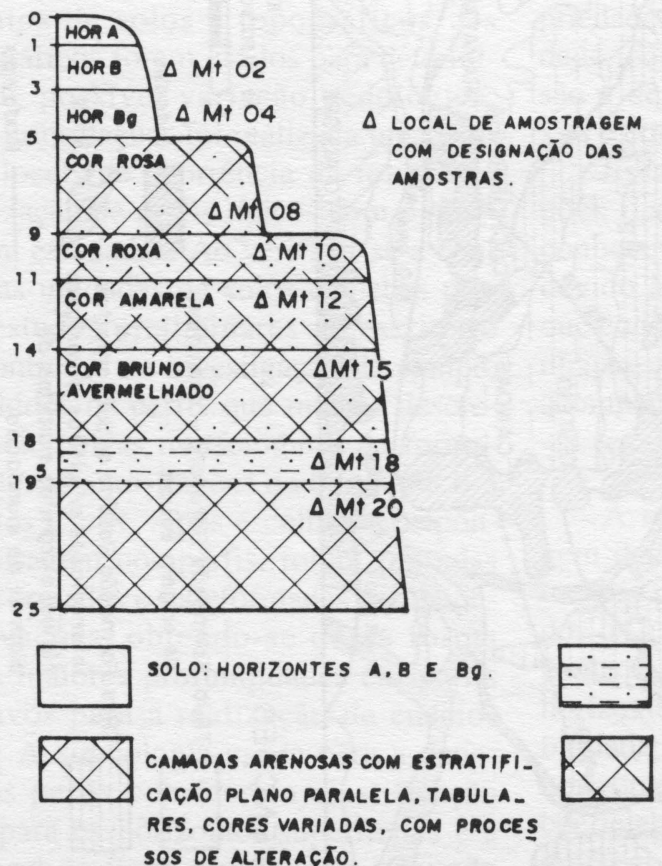
SOS dE ALTERAÇÃo

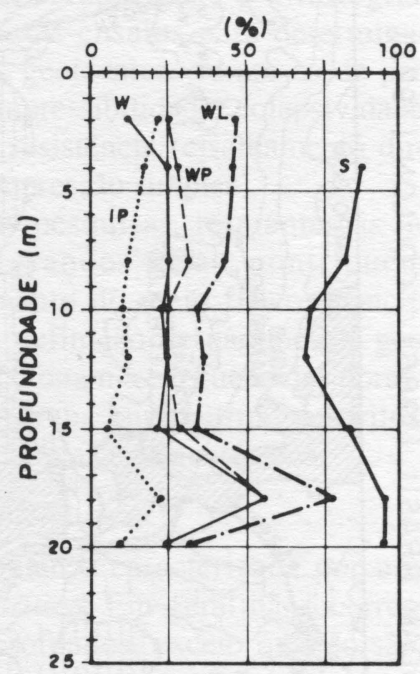

CAMADA FRANCO-SILTOSA, PELÍTICA, POROSA, COM SURGÉnCIA de ÁGUA.

ARENITO, COR ROXA, COM POUCA ALTERACTOO

\begin{tabular}{|c|c|c|c|c|c|c|c|c|c|}
\hline Simb. & Hor. & $\begin{array}{c}\text { Ar.Fina } \\
(\%)\end{array}$ & $\begin{array}{c}\text { Silte } \\
(\%)\end{array}$ & $\begin{array}{c}\text { Argila } \\
(\%)\end{array}$ & $\begin{array}{c}\text { Ac } \\
(\%)\end{array}$ & Gs & $\begin{array}{c}\gamma \text { nat } \\
\left(\mathrm{kN} / \mathrm{m}^{3}\right)\end{array}$ & $\begin{array}{c}\gamma \mathrm{d} \\
\left(\mathrm{kN} / \mathrm{m}^{3}\right)\end{array}$ & e \\
\hline $\mathrm{Mt02}$ & $\mathrm{B}$ & 40 & 27 & 32 & 0.69 & 2.68 & - & - & - \\
\hline $\mathrm{Mt04}$ & $\mathrm{B}$ & 40 & 28 & 30 & 0.61 & 2.67 & 19.0 & 15.2 & 0.75 \\
\hline $\mathrm{Mt08}$ & $\mathrm{C}$ & 50 & 39 & 11 & 1.09 & 2.62 & 17.9 & 14.2 & 0.85 \\
\hline $\mathrm{Mt10}$ & $\mathrm{C}$ & 54 & 35 & 10 & 1.00 & 2.66 & 17.5 & 14.2 & 0.87 \\
\hline $\mathrm{Mt12}$ & $\mathrm{C}$ & 58 & 33 & 9 & 1.33 & 2.68 & 17.2 & 14.1 & 0.95 \\
\hline $\mathrm{Mt15}$ & $\mathrm{C}$ & 63 & 22 & 14 & 0.35 & 2.63 & 18.9 & 15.5 & 0.69 \\
\hline $\mathrm{Mt18}$ & $\mathrm{C}$ & 23 & 52 & 14 & 0.96 & 2.86 & 16.5 & 10.6 & 1.70 \\
\hline $\mathrm{Mt} 20$ & $\mathrm{R}$ & 62 & 30 & 7 & 1.28 & 2.63 & 19.5 & 15.7 & 0.67 \\
\hline
\end{tabular}

FIGURA 2 - Características do perfil PVa - podzólico vermelho-amarelado com substrato arenito (a) - Esquema do perfil.

(b) - Variação das características de plasticidade, umidade natural e grau de saturação.

(c) - Tabela de granulometria, atividade coloidal e índices físicos. 
taludes, com conseqüentes desmoronamentos. Recomendam-se para evitar estes problemas, quando há presença de água, um sistema de drenagem adequado e uma cobertura vegetal nos taludes. Verificou-se no campo que inclinações dos taludes, em cortes nos arenitos de 1:1 e nos siltitos e argilitos de 1:1.5, apresentavam-se muitas vezes rompidas. Durante chuvas intensas ocorre uma diminuição da resis- tência ao cisalhamento dos solos parcialmente saturados com o aumento do grau de saturação. Há um aumento da tensão cisalhante atuante, uma diminuição da parcela de sucção, ocorrendo muitas vezes um excesso de pressão neutra positiva, com um decréscimo na tensão cisalhante resistente. Estudos geotécnicos pontuais devem ser realizados para evitar estes problemas.

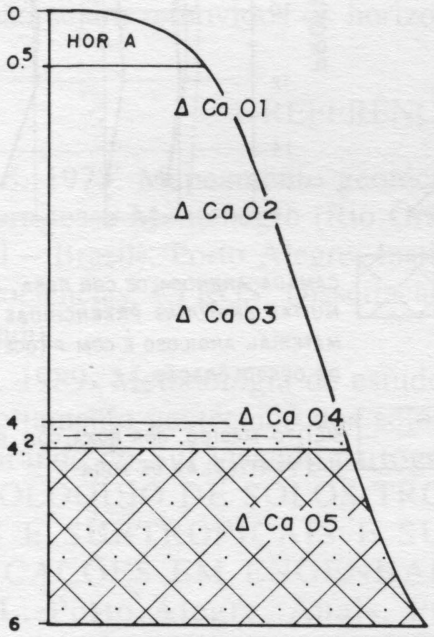

HORIZONTE B, COR VERMELHO ES CURO, COM MUITAS CONCRE ÇŌES FERRUGINOSAS

CAMADA ARGILO-SÍLTICA, COR AVER MELHADA, ESTRUTURA LAMINAR

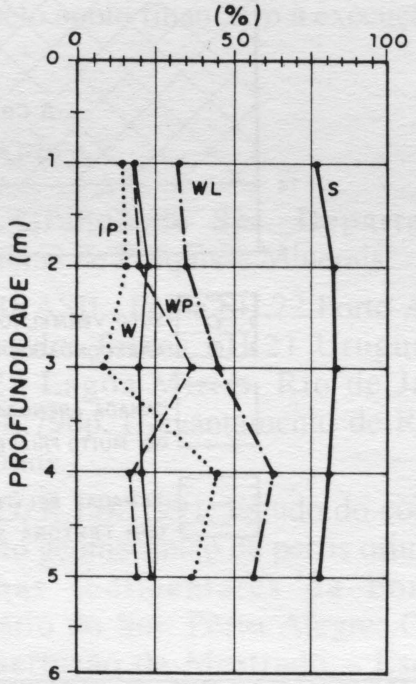

AMADA ARGILO-ARENOSA, COR ROSA, COM SUTIL LAMINAÇ̃̃o PLANO PARALE LA, COM MUITA MICA.

$\triangle$ LOCAL DE AMOSTRAGEM COM DESIGNA ÇÃO DAS AMOSTRAS.

\begin{tabular}{|c|c|c|c|c|c|c|c|c|c|}
\hline Simb. & Hor. & $\begin{array}{c}\text { Ar.Fina } \\
(\%)\end{array}$ & $\begin{array}{c}\text { Silte } \\
(\%)\end{array}$ & $\begin{array}{c}\text { Argila } \\
(\%)\end{array}$ & $\begin{array}{c}\text { Ac } \\
(\%)\end{array}$ & Gs & $\begin{array}{c}\gamma \text { nat } \\
\left(\mathrm{kN} / \mathrm{m}^{3}\right)\end{array}$ & $\begin{array}{c}\gamma \mathrm{d} \\
\left(\mathrm{kN} / \mathrm{m}^{3}\right)\end{array}$ & e \\
\hline $\mathrm{Ca} 01$ & B & 34 & 34 & 31 & 0.48 & 2.66 & 19.3 & 16.3 & 0.63 \\
\hline $\mathrm{Ca} 02$ & B & 39 & 21 & 39 & 0.41 & 2.68 & 18.9 & 15.4 & 0.74 \\
\hline $\mathrm{Ca} 03$ & B & 30 & 31 & 37 & 0.24 & 2.63 & 19.3 & 16.0 & 0.65 \\
\hline $\mathrm{Ca} 04$ & $\mathrm{C}$ & 7 & 45 & 48 & 0.96 & 2.63 & - & - & - \\
\hline $\mathrm{Ca} 05$ & $\mathrm{C}$ & 36 & 25 & 39 & 0.97 & 2.66 & 17.5 & 14.1 & 0.80 \\
\hline
\end{tabular}

FIGURA 3 -Características do Perfil PEag - Podzólico vermelho-escuro com substrato argilito.

(a) - Esquema do perfil.

(b) - Variação das características de plasticidade, umidade natural e grau de saturação.

(c) - Tabela de granulometria, atividade coloidal e índices físicos. 


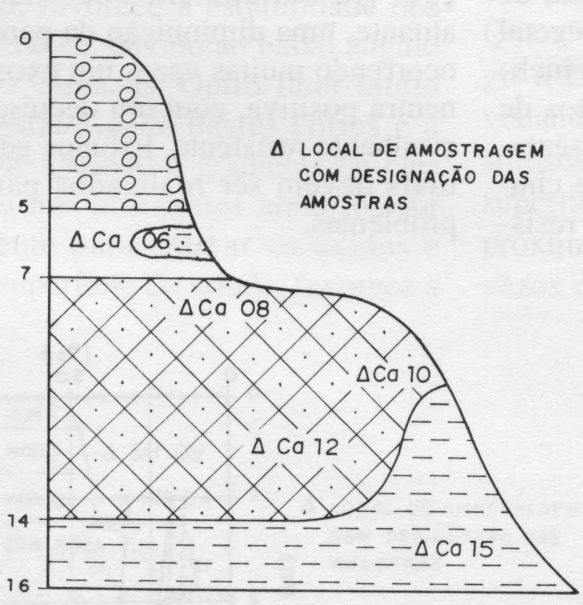

SOLO VERMELHO OXIDADO COM SEIXOS ARREDONDADOS BEM ALTERADOS.

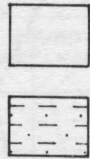

CAMADA ARENOSA, BRUNO AVERMELHA DO, MUITO FRIÁVEL C/ POUCA CIMENT.

CAMADAS PELÍ́TICAS, DE COR ROXA. COM TEXTURA SILTOSA.

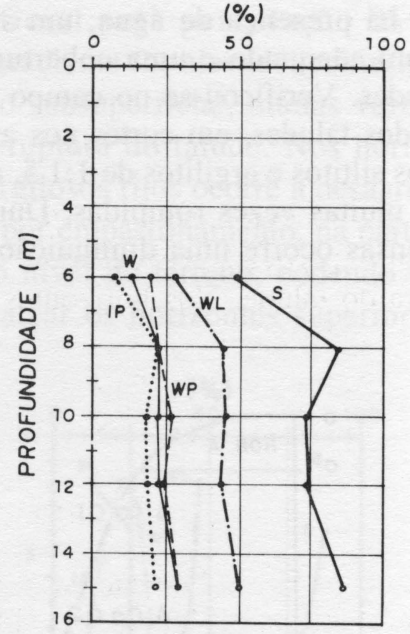

CAMADA ARENOSA, DE COR ROSA, COM MUITAS FRATURAS PREENCHIDAS POR MATERIAL ARGILOSO E COM PROCESSO DE DESCOLORAÇĀO

SILTITO MACIÇO, COR ROXA, COM PEQUE NAS PARTÍCULAS DE MICA.

\begin{tabular}{|c|c|c|c|c|c|c|c|c|c|}
\hline Simb. & Hor. & $\begin{array}{c}\text { Ar.Fina } \\
(\%)\end{array}$ & $\begin{array}{c}\text { Silte } \\
(\%)\end{array}$ & $\begin{array}{c}\text { Argila } \\
(\%)\end{array}$ & $\begin{array}{c}\text { Ac } \\
(\%)\end{array}$ & Gs & $\begin{array}{c}\gamma \text { nat } \\
\left(\mathrm{kN} / \mathrm{m}^{3}\right)\end{array}$ & $\begin{array}{c}\gamma \mathrm{d} \\
\left(\mathrm{kN} / \mathrm{m}^{3}\right)\end{array}$ & e \\
\hline $\mathrm{Ca} 06$ & $\mathrm{C}$ & 72 & 11 & 13 & 0.62 & 2.67 & 17.8 & 15.8 & 0.69 \\
\hline $\mathrm{Ca} 08$ & $\mathrm{C}$ & 60 & 27 & 12 & 1.83 & 2.62 & 18.7 & 15.1 & 0.74 \\
\hline $\mathrm{Ca} 10$ & $\mathrm{C}$ & 56 & 29 & 15 & 1.27 & 2.62 & 18.0 & 14.8 & 0.77 \\
\hline $\mathrm{Ca} 12$ & $\mathrm{C}$ & 52 & 28 & 20 & 1.00 & 2.64 & 17.9 & 14.6 & 0.80 \\
\hline $\mathrm{Ca} 15$ & $\mathrm{R}$ & 23 & 58 & 18 & 1.22 & 2.67 & 18.3 & 14.4 & 0.88 \\
\hline
\end{tabular}

FIGURA 4 - Características do Perfil Ra,s - litólico com substrato arenito e siltito.

(a) - Esquema do perfil.

(b) - Variação das características de plasticidade, umidade natural e grau de saturação.

(c) - Tabela de granulometria, atividade coloidal e índices físicos.

\subsection{Condições de fundação}

Em geral as condições de fundação são boas, adotando-se fundações diretas. Salienta-se que a escolha depende essencialmente das magnitudes das cargas e da compacidade e consistência das camadas de fundação. Deve-se esperar nesta formação uma grande heterogeneidade na deposição das camadas, ocorrendo muitas vezes camadas argilosas e siltosas entre os arenitos. Nos solos arenosos, os parâmetros de resistência são muito variáveis. São influenciados pelo intemperismo, pelo grau de cimentação e pelo grau de saturação.

\section{CONCLUSÃO}

A Formação Rosário do Sul apresenta geralmente perfis com boa capacidade de carga 
quanto à fundação superficial; entretanto, cuidados devem ser considerados quanto à exposição do horizonte $\mathrm{C}$ aos processos de molhagem e secagem, devido ao caráter expansivo muitas vezes presente neste horizonte. Geralmente os cortes feitos em solos oriundos de arenito são estáveis nesta formação; entretanto, com um elevado gradiente hidráulico, pode ocorrer uma erosão subsuperficial, provocando muitas vezes a ruptura do talude. Nos horizontes siltosos e argilosos rijos pode ocorrer uma desagregação superficial por empastilhamento. Portanto, desde que não sejam removidos os horizontes superficiais argilosos (horizonte B), a estabilidade dos cortes é boa, mantendo-se as inclinações dos taludes nos valores recomendados na prática. Em geral não ocorre ravinamento profundo nesta formação, exceto quando é removido o horizonte superficial, A e B, deixando o horizonte $\mathrm{C}$ exposto às intempéries.

\section{AGRADECIMENTOS}

Os autores agradecem à FAPERGS, CNPq e FINEP pelo apoio financeiro à execução deste trabalho.

\section{REFERÊNCIAS BIBLIOGRÁFICAS}

COULON. S. 1973. Mapeamento geotécnico de Morrotes e Montenegro (Rio Grande do Sul - Brasil). Porto Alegre, Instituto de Geociências, UFRGS. Dissertação de Mestrado.

DIAS, R.D. 1989. Metodologia de estudo do comportamento geotécnico dos solos do Rio Grande do Sul visando cartografia In: COLÓQUIO DE SOLOS TROPICAIS E SUBTROPICAIS E SUAS APLICAÇÕES EM ENGENHARIA CIVIL. Porto Alegre. Anais. Porto Alegre: CPGEC/UFRGS, p. 228-247.

DIAS, R.D.\& MILITITSKI, J. 1990. Proposta de um Sistema de Classificação de Unidades Geotécnicas e Definição de Perfis Compostos de Solos Tropicais e Subtropicais. Publicação Interna. CPGEC/UFRGS. Porto Alegre.

DNPM. 1989. Mapa geológico do Estado do
Rio Grande do Sul. Departamento Nacional de Pesquisas Minerais.

RADAMBRASIL. Folha SH.22 Porto Alegre e parte das folhas SH.21 Uruguaiana e SI:22 Lagoa Mirim. Rio de Janeiro: IBGE.796p. (Levantamento de Recursos Naturais.)

PINHEIRO, R.J.B. 1991. Estudo do comportamento geomecânico de perfis oriundos de rochas sedimentares da Formação Rosário do Sul. Porto Alegre: CPGEC. Dissertação de Mestrado - Escola de Engenharia, UFRGS.

ZUQUETTE, L. V. \& GANDOLFI, N. 1987. Metodologia de mapeamento geotécnico para áreas municipais. In: CONGRESSO BRASILEIRO DE GEOLOGIA DE ENGENHARIA, 5ํㅜ 1987. São Paulo. Anais. São Paulo: ABGE, v.2, p. 303312.

- Rinaldo José Barbosa Pinheiro - R. Prof. Teixeira, 1.580 - ap. 205 - 97015-550 - Santa Maria - RS.

- Regina Davison Dias - CPGEC/Universidade Federal do Rio Grande do Sul - Av. Osvaldo Aranha, 99 - 3ํandar - $90210-000$ - Porto Alegre - RS - Brasil. 